\title{
USING STRUCTURES TO TEACH LEGAL REASONING
}

\author{
DUNCAN BENTLEY*
}

\section{INTRODUCTION}

In 1992, The American Bar Association Task Force Report on legal education and professional development was published. ${ }^{1}$ Part of the central mission of the Task Force was to identify the skills and values required by a competent lawyer. ${ }^{2}$ Ten skills were identified. The second of these is legal analysis and reasoning. ${ }^{3}$ Legal reasoning is usually a fundamental element in the teaching and understanding of law in common law countries. ${ }^{4}$ In most core substantive law courses this takes place at least in part through a study of cases and the use of standard undergraduate problems. ${ }^{5}$ These problems are generally fairly straightforward fact patterns designed to raise one or more issues within a specific area of law.

At Bond University specific structures are generally used in teaching legal reasoning. The hypothesis underlying their use is that students using such structures will improve their legal reasoning. The first part of this article describes an experiment ${ }^{6}$ to test the use by students of one such structure. ${ }^{7}$

The second part of this article gives the results of the research, which are categorised according to the aims, and a discussion of those results. The aims are categorised as follows:

- whether students used the structure taught

- whether students using the structure, applied it well and if not, why not

- whether students using the structure applied it consistently

- whether students' application of the structure improved 
- whether it could be shown that students' marks improved as a result of using the structure.

The third part of this article draws some conclusions as to the weight which should be placed on unstructured anecdotal evidence in assessing success in teaching methods; discusses some difficulties in teaching legal reasoning to undergraduates; and places the results of this experiment in context.

\section{Part 1: Research Into the Use of a Structure in Teaching Legal Reasoning}

\section{BACKGROUND}

\section{What Structure?}

Law teachers spend a good deal of time helping their students to understand and apply the process of legal reasoning. The common undergraduate problem used in law school tutorials and examinations has as its primary objective, the testing of a "student's ability to recognize and articulate legal issues in a fact pattern and to give a reasoned opinion about which party would succeed should the facts be placed before a judge". ${ }^{8}$ Various structures have been used to break down the reasoning process into its component parts in order to facilitate a greater understanding of it. $^{9}$ At Bond University, the School of Law uses variations of the method of problem solving described by the acronym MIRAT. ${ }^{10}$ The acronym stands for:

$$
\begin{aligned}
\mathrm{M} & - \text { material/missing facts } \\
\mathrm{I} & - \text { issues } \\
\mathrm{R} & - \text { rule (principle) of law } \\
\mathrm{A} & - \text { application/argument } \\
\mathrm{T} & - \text { tentative conclusion }
\end{aligned}
$$

The key to its success is its simplicity, which makes it sufficiently adaptable for use in most undergraduate law subjects.

Particularly in examinations, where there are often severe time constraints, but in considering any fact pattern, many students find that they only really identify the material/ missing facts once they have determined the issues and the applicable rules of law. Identification of material/missing facts can be seen as a continuum. 
With most fact patterns there are some obviously material/missing facts. Depending on the level of expertise of the student, these should be identified early on in the reasoning process. Other facts are less obviously material/missing and would generally be recognised as such after the identification of the issues. Further material/missing facts would likely only become evident after consideration of possible sub-issues. Experience in teaching MIRAT at Bond has shown that many students find it confusing to have to identify material/missing facts first, when they keep finding new material/missing facts as they progress through the reasoning process.

To help students cope with this process, and as a variation on MIRAT, Kay Lauchland ${ }^{11}$ has put forward the idea of a spiral. Students, when faced with a fact pattern, should ask themselves:

- on the basis of the facts given, what law do I know that is vaguely relevant?

- what issues do I think I should address? What facts then, are material?

Having done this, students should then be in a position, in written form, to:

- restate the Issues I

- define the Rules $\mathrm{R}$

- Apply the rules A

- to the Facts F

- reach a Tentative conclusion $\mathrm{T}$

The final step is to ask if any other facts are material/ missing and start the process again: hence the spiral concept. The written element of this format gives the acronym IRAFT.

This is one possible approach, and is the approach studied in this paper. Whatever the structure chosen, the question remains as to whether using such structures to teach legal reasoning actually works.

\section{Scope of the Research}

To answer that question, I commenced research into the effectiveness of using the IRAFT structure in teaching legal reasoning. ${ }^{12}$ Extensive discussions were held with fellow faculty members at Bond University. From the queries and perceived problems raised by members of faculty it was possible to isolate 
certain key considerations which would form the basis for the research.

When examined in the context of a course in which students are being taught legal reasoning using the IRAFT structure, these considerations could be set out as follows:

- Do students use IRAFT?

- Of those students who use IRAFT, how well do they use it?

- Of those students who use IRAFT, how consistently do they use it?

- Of those students who use IRAFT, did their use of it improve over time?

- If they use IRAFT, does it improve their marks?

For some faculty members there was a skepticism as to the usefulness of structures to assist students in the legal reasoning process, particularly in examinations. For these faculty members there was a feeling that the quality of the answers given, whether or not a structure was used, fell below the faculty members' expectations.

\section{THE RESEARCH SAMPLE ${ }^{13}$}

\section{The Sample Group and Why It Was Chosen}

The research was conducted during a taxation law course. Most students would take taxation law about half way through their law degree, but the sample group included students from their second to eighth (final) semester. Accordingly, they would, in .most cases, have had reasonable exposure to law subjects including teaching on the use of basic structures to assist in legal reasoning and analysis. The basic structure used would in almost all cases have been MIRAT or a variation such as IRAFT.

It was felt that using a course with most students in the middle of their degree would be useful. The students should have overcome any initial culture shock they may have had in a first year course, which could have distorted the results. ${ }^{14}$ This meant that the research was aimed at discovering whether IRAFT is appropriate as a tool for students, with a basic knowledge of law, to use in helping them to give structure to their own process of legal reasoning.

Another advantage in using a mid-degree course was that the emphasis on legal reasoning and analysis in the early part of their 
degree should have firmly established the importance and some experience of these skills in the students' minds. This observation is based on schema theory, which is fundamental to my analysis of students' use of structures in their legal reasoning. Schema theory argues that in every aspect of human experience we develop patterns to explain the relationship between the different elements of those experiences; to impose an order on our sensory input. ${ }^{15}$ On entering any new field of knowledge, we have to build up an interpretive framework, based on past knowledge and experience, that allows us "to make sense out of the bits and pieces of information presented to us in given situations". ${ }^{16}$ Novices in any area have limited knowledge and experience. Long periods of learning and experience are required to build up expert knowledge structures. ${ }^{17}$ Law is no exception and students entering law school have to build up a "legal" interpretive framework. ${ }^{18}$

This can be particularly traumatic for students with high level interpretive frameworks, which have worked well for them in other fields, when they are faced with the demand to develop a new interpretive framework as they commence their study of law. ${ }^{19}$ Using a mid-degree course ensures that this initial trauma should not affect results and the students should have developed beyond the lowest level novice interpretive framework.

Taxation law was in many ways an ideal course to use in the research. It is strongly statute based, to an extent not found in most of the earlier courses taken by students. In this sense a student's interpretive framework built up in the early part of the law degree needs to be adapted to cope with what is effectively a new rule structure. This provides an ideal opportunity to test the students' legal reasoning skills as they approach a different style of problem and adapt and expand their interpretive frameworks.

\section{Possible Problems with the Research Sample: The Ethical Issue ${ }^{20}$}

The ethical issue of using students to assist in research of this kind was recognised by explaining to students in detail the nature of the research and asking students who did not wish to participate to indicate this to the lecturer or their tutor. It was stressed that participation or otherwise would in no way affect assessment of students' performance. This last assertion was given further weight 
in that all written work and examination scripts are marked blind in the School of Law. Only the student number must appear on the script.

No students indicated an unwillingness to participate. In fact only 50 out of the 146 students enrolled for the course completed all three written elements used in the research, although 101 students completed at least one of the two non-compulsory elements of the research. Students at Bond University have a three semester year. They usually complete four pieces of assessment during each semester and have weekly tutorials, at which their performance is assessed. A number of students stated that pressure of work prevented them from completing the first two written elements used in the research. This would suggest that nonparticipation could be attributed to pressure of work, rather than an unwillingness to participate.

\section{Possible Problems with the Research Sample: The Hawthorne Effect}

The Hawthorne effect ${ }^{21}$ suggests that knowingly being part of an experiment can improve performance so as to distort the results. Otherwise known as expectancy bias, it has been shown in a wide range of experiments that the expectations of the experimenter can be transmitted to the subjects and can powerfully influence the subjects' responses. ${ }^{22}$

It is suggested that the methodology used in this experiment would not have produced sufficient distortion to invalidate the results. The process was part of the ordinary teaching program and no mention was made of the experiment after the initial explanations. Students participating indicated verbally that they valued the opportunity to practise exam type questions and to obtain feedback. Similar opportunities are available to students every semester. The likelihood of distortion with respect to the examination question that formed part of the experiment is particularly low. Students did not know which examination question would be used in the experiment and their incentive to do well in the examination to attain a high grade was far greater than any incentive they may have had as participants in the experiment. 


\section{METHODOLOGY}

\section{Legal Reasoning in Standard Problems}

Three standard undergraduate problems ${ }^{23}$ were completed by students in the sample group as part of the ordinary teaching program. The first two were handed out in weeks 7 and 11, and students had a week to complete them. The third was part of the examination in week $14 .{ }^{24}$ All three were of a similar level of difficulty. Scripts from the first two problems were returned to students with limited written feedback, but a full model answer using the IRAFT structure was provided.

\section{Reinforcement Through Teaching and Learning}

In the course of a two hour lecture in week 7 the lecturer reviewed the use of the IRAFT model and demonstrated it using several examples. During the ten hours of lectures over the final five weeks of the course, the lecturer continued to demonstrate the use of IRAFT using examples in each lecture. The examples chosen covered both simple, single issue problems and complex, multiple issue problems.

Small group tutorials ${ }^{25}$ were also carried out over this period, in which students were sometimes given a complete written problem and sometimes had to seek further information with respect to the problem in order to be able to analyse it properly and formulate possible solutions. A mixture of directed questioning by the tutor, demonstration and student-lead learning was used. ${ }^{26}$ Guidance was provided by tutors in ensuring an understanding of the legal reasoning process used in answering the tutorial problems. Any demonstration of the legal reasoning process by tutors used the IRAFT structure.

\section{Collation and Assessment of Results}

The collation and assessment of the research questions and the assessment of the exam questions for research purposes, took place in the following semester. ${ }^{27}$ Each of the answers to the questions was marked out of ten. Marks were recorded by student number. A sample of the marks was checked by another lecturer marking 
blind. The sample showed a difference in the marks between the original and the second marker of an average of less than one quarter of a mark, with no single variation greater than one mark. ${ }^{28}$ Accordingly, the marks given have been assumed to be reliable and consistent. $^{29}$

All scripts were then reviewed for a second time by the lecturer, again by student number and without reference to the mark given for each script. This time it was to determine whether the IRAFT structure or any other structure had been used in answering each question and if so, how well it had been used. Note was also made of which aspect of the structure identified had been used inadequately in answering the question. The use of the structure was classified as good, satisfactory or poor. Any more detailed classification would have been too subjective to provide adequate data. $^{30}$

The marks and rankings as to the use of a structure were then entered into a composite spreadsheet for each of the answers to the three questions. The student numbers were then removed to give anonymous raw data.

It was found that only 50 out of 146 students had completed all three questions used in the experiment. This group of 50 students was used as the core sample for analysis. The results are set out in Figures 1 and 2.

All three problems required the consideration of only one major issue and the consideration of two or three main rules. The authority for those rules was based in case law and statute. There were a number of different cases which could have been cited as authority, but only one section or sub-section of the statute was applicable. The problems were of average difficulty for an undergraduate subject. A good answer using an IRAFT approach would have to show an understanding of the issue involved, the relevant rules of law and their application to the particular facts in question, drawing a valid tentative conclusion on the basis of a well reasoned argument. An example of an answer to a problem using the IRAFT approach is set out in Appendix A. 


\section{PART 2: ANALYSIS AND DISCUSSION OF RESULTS}

The results are drawn from the raw data, which is summarised in Figures 1 and 2, and from basic regression analysis performed to identify statistical correlation and relationship(s). ${ }^{31}$

FIGURE 1 : Table Showing the Use of Method and Marks Achieved by Students Participating in the Experiment

\begin{tabular}{|c|c|c|c|c|c|c|}
\hline & \multicolumn{2}{|c|}{ Question 1} & \multicolumn{2}{|c|}{ Question 2} & \multicolumn{2}{|c|}{ Exam Question } \\
\hline $\begin{array}{l}\text { Use of } \\
\text { method }\end{array}$ & $\begin{array}{l}\text { No of } \\
\text { students }\end{array}$ & $\begin{array}{l}\% \text { of } \\
\text { total (out } \\
\text { of } 50 \text { ) }\end{array}$ & $\begin{array}{l}\text { No of } \\
\text { students }\end{array}$ & $\begin{array}{l}\% \text { of } \\
\text { total (out } \\
\text { of } 50 \text { ) }\end{array}$ & $\begin{array}{l}\text { No of } \\
\text { students }\end{array}$ & $\begin{array}{l}\% \text { of } \\
\text { total (out } \\
\text { of } 50 \text { ) }\end{array}$ \\
\hline
\end{tabular}

Good

Marks out of 10

\begin{tabular}{|c|c|c|c|c|c|c|}
\hline $8-10$ & 15 & 30 & 11 & 22 & 15 & 30 \\
\hline $5-7$ & 9 & 18 & 14 & 29 & 17 & 34 \\
\hline$<5$ & 1 & 2 & 1 & 2 & - & - \\
\hline Total good & 25 & 50 & 26 & 52 & 32 & 64 \\
\hline
\end{tabular}

Satisfactory

Marks out of 10

$8-10$

$\begin{array}{lllllll}5-7 & 9 & 18 & 13 & 26 & 11 & 22\end{array}$




\begin{tabular}{|c|c|c|c|c|c|c|}
\hline$<5$ & 2 & 4 & 5 & 10 & 1 & 2 \\
\hline $\begin{array}{l}\text { Total } \\
\text { satisfactory }\end{array}$ & 11 & 22 & 18 & 36 & 12 & 24 \\
\hline \multicolumn{7}{|l|}{ Poor } \\
\hline \multicolumn{7}{|c|}{ Marks out of 10} \\
\hline $8-10$ & - & - & - & - & - & - \\
\hline $5-7$ & 2 & 4 & 1 & 2 & 2 & 4 \\
\hline$<5$ & 1 & 2 & 1 & 2 & 2 & 4 \\
\hline Total poor & 3 & 6 & 2 & 4 & 4 & 8 \\
\hline
\end{tabular}

Other Methods

Marks out of 10

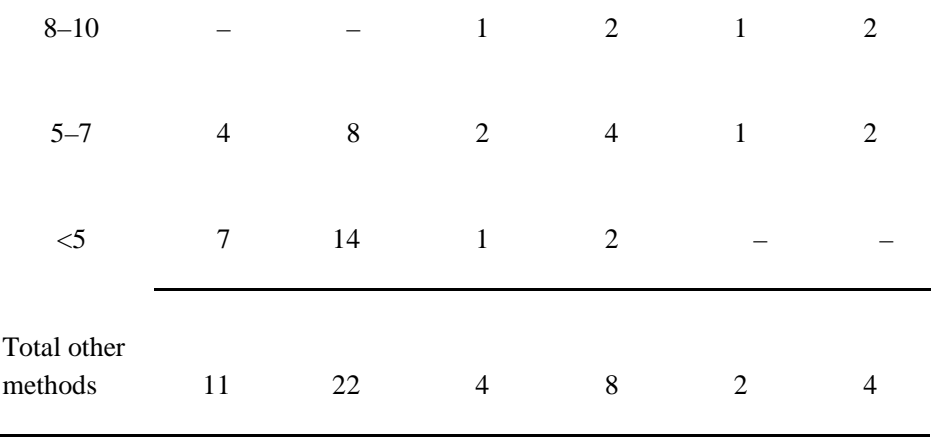

FIGURE 2: Table Showing a Summary of the Marks Achieved by Students Participating in the Experiment

Question 1

Question 2

Exam Question 


\begin{tabular}{|c|c|c|c|c|c|c|}
\hline $\begin{array}{l}\text { Mark } \\
\text { Summary }\end{array}$ & $\begin{array}{l}\text { No of } \\
\text { students }\end{array}$ & $\begin{array}{l}\% \text { of } \\
\text { total (out } \\
\text { of } 50 \text { ) }\end{array}$ & $\begin{array}{l}\text { No of } \\
\text { students }\end{array}$ & $\begin{array}{l}\% \text { of } \\
\text { total (out } \\
\text { of } 50 \text { ) }\end{array}$ & $\begin{array}{l}\text { No of } \\
\text { students }\end{array}$ & $\begin{array}{l}\% \text { of } \\
\text { total (out } \\
\text { of } 50 \text { ) }\end{array}$ \\
\hline
\end{tabular}

Good

Marks out of 10

\begin{tabular}{lrrrrrr}
$8-10$ & 15 & 30 & 12 & 24 & 16 & 32 \\
& & & & & & \\
$5-7$ & 24 & 45 & 30 & 60 & 31 & 62 \\
& & & & & & \\
& 11 & 22 & 8 & 16 & 3 & 6 \\
\cline { 2 - 7 } $\begin{array}{l}\text { Total } \\
\text { students }\end{array}$ & 50 & 100 & 50 & 100 & 50 & 100 \\
\hline
\end{tabular}

ANALYSIS OF RESULTS

\section{Did Students Use the Structure Taught?}

From Figure 1 it can be seen that in the first question, 22\% of students used either a method other than IRAFT or a method not discernible to the markers. The percentage decreased to $8 \%$ in the second question and to $4 \%$ in the exam question. Of those students who did not use IRAFT, only one student used an alternative discernible structure which remained consistent for all three questions.

The results are not surprising following a period of teaching and learning which emphasised the usefulness of the IRAFT structure in the legal reasoning process. Similar results could be expected whatever the structure taught. Students would tend to use any technique demonstrated and affirmed by a lecturer who is setting assessment which they have to pass. ${ }^{32}$ It is interesting to note that only one of the students showed sufficient confidence in her/his legal reasoning process to develop and use consistently and successfully her/his own structure. 


\section{Did Students Using the Structure, Use It Well, and If Not, Why Not?}

Of the students who used IRAFT, the percentage whose use was "good" was $64 \%$ for the first question, ${ }^{33} 56 \%$ for the second question, ${ }^{34}$ and $67 \%$ for the exam question ${ }^{35}$. In contrast, the percentage of students whose use of IRAFT was “poor”, was $8 \%$ for the first question, ${ }^{36} 4 \%$ for the second question ${ }^{37}$ and $8 \%$ for the exam question. ${ }^{38}$

The 150 answers were analysed to ascertain any area where the use of IRAFT was not "good". This analysis included answers by students whose overall use of the structure was "good". In 28 answers, students had difficulty identifying the appropriate rules, while in 27 answers they had difficulty applying the appropriate rules to the material facts. In a further 50 answers, students had difficulty both in identifying the appropriate rules and applying them to the material facts. In only nine of the 150 answers was there a problem in identifying the relevant issues.

Clearly a majority of students find the structure simple to understand and to use well. This suggests that IRAFT is very successful as a simple structure to help students in the legal reasoning process. However, in using the structure, students have most difficulty in identifying the appropriate rule to apply and then in actually applying the rule to the material facts. The structure does not assist with carrying out these aspects of the legal reasoning process other than to identify them as steps in the process.

It is not the purpose of this article to move to the next step and try and explain why students have difficulties with rule identification and application. Mitchell ${ }^{39}$ believes that it is because students are in the early stages of moving along a continuum, which starts with the "novice" interpretive framework of the first year law student and moves to the "expert" interpretive framework of the practising lawyer. His article provides useful suggestions for law teachers to help students develop their thinking processes. ${ }^{40}$ However, further research is required to explore and test the validity of these ideas.

It could be argued that the use of a successful structure may encourage students to adopt a surface approach. This may well be 
so. However, the structure is merely a model or scheme to assist students with a limited legal knowledge base to cope with the organisation and manipulation of large amounts of information in areas with which they are unfamiliar. Structures to help in the legal reasoning process are tools to be used by teachers in the development of expert interpretive frameworks in their pupils. It is the role of the teacher to go beyond the mere provision of a structure. Glaser sees a form of interrogation and confrontation of basic structures as essential to the development of any student's knowledge base.

Such structures, when they are interrogated, instantiated, or falsified, help organize new knowledge and offer a basis for problem solving that leads to the formation of more complete and expert schemata. The process of knowledge acquisition can be seen as the successive development of structures which are tested and modified or replaced in ways that facilitate learning and thinking. ${ }^{41}$

\section{Did Students Using the Structure use it Consistently?}

There was a correlation between the "good" use of IRAFT by students in question 1 and their "good" use of it in question 2. However, there was no such correlation between the "good" use of IRAFT in question 1 and its subsequent "good" use by those students in the exam question. There was a correlation between the "good" use of IRAFT in question 2 and its subsequent "good” use by those students in the exam question.

What can be suggested from this is that using the IRAFT method well in one question did not guarantee its being used well in subsequent questions. A skill is only acquired with practice. It would have been interesting to see whether the correlation between a "good" use of IRAFT in the second question and the exam question would have continued for a third question, given that students would then have had more practice in using the structure.

Did Students' Use of the Structure Improve? For the first question, 39 of the 50 students used IRAFT. This increased to 46 students for the second question and 48 students for the exam question. Of those not using IRAFT only one student used an identifiable alternative structure consistently over more than one question. 
It can be seen from the results to the question, "did students using the structure, use it well, and if not, why not?" that the percentage of students whose use of IRAFT was "good" did not increase significantly. However, it is interesting to note that of the nine students who changed from another or no discernible method in the first question, to using IRAFT in the second question, ${ }^{42}$ only two showed a "good" use of IRAFT. Subsequently, in the exam question, six of those nine students showed a "good" use of IRAFT.

The fact that only one student consistently used an identifiable structure other than IRAFT, suggests that it could be reasonable to test the improvement in use of IRAFT over 49 students for all three questions. This would show that students with a "good" use of IRAFT would be $51 \%$ for the first question, 53\% for the second question and $65 \%$ for the exam question. This does show an improvement by students in their use of an identifiable structure. It is also consistent with an expected improvement in performance as the students practised the skill of using the structure in the legal reasoning process.

\section{Did Students’ Marks Improve as a Result of Using the Structure?}

From an analysis of pure marks over the three questions there was no statistically significant correlation. ${ }^{43}$ However, there appears to be a trend showing that students generally improved their performance over the three questions.

For each individual question, it was clear that students who achieved good marks tended to show a "good" use of IRAFT in their answers. There was an extremely strong correlation between the two. ${ }^{44}$ In an analysis of the use of IRAFT in all three questions looked at together, there was an extremely strong correlation between the achievement of a high mark and the "good use of IRAFT. ${ }^{45}$

It is interesting to note further, that of the $32 \%$ of students achieving $80 \%$ or more for the exam question, all showed a "good" use of IRAFT or another method. Students who did not show "good" use of a structure did not achieve over $70 \%$.

The results did not show that students who showed "good" use of IRAFT in an earlier question consistently achieved higher marks in the later questions. It was shown to be generally true that a 
student who showed "good" use of IRAFT in the first question in week 8, did achieve good marks in the second question in week 12. ${ }^{46}$ However, neither a student who showed "good" use of IRAFT in the first question in week $8,{ }^{47}$ nor a student who showed "good" use of IRAFT in the second question in week 12, ${ }^{48}$ necessarily scored a high mark in the exam in week 14 . So the closeness of the second question to the exam did not necessarily help students who showed "good" use of IRAFT in the second question to use it well enough in the exam to obtain a high mark.

There is clearly a very consistent relationship between using a structure skilfully in an answer and achieving a high mark. However, as discussed above, students who showed that they could use the structure skilfully, did not necessarily do so consistently.

\section{DISCUSSION OF RESULTS}

The use of IRAFT or any other structure to help in the analysis of legal fact patterns and the process of legal reasoning is largely an acquired skill. As with any skill, natural talent can enhance it and for some people it comes more easily than others. The effective use of a skill is likely to diminish under pressure. The students' use of IRAFT is largely consistent with these observations.

\section{Students Not Using IRAFT}

A good application of IRAFT is likely to produce a better result for the student. For those students who did not use IRAFT, it was only those who used a discernible alternative structure who achieved pass marks. Most of the students who started out with an alternative or no discernible structure subsequently adopted IRAFT in their answers (the number not using IRAFT shrank from 22\% in the first exercise to $4 \%$ in the exam) and by the exam there was a significant improvement in their marks.

Of the two students who did not use IRAFT in the exam, one used a structure which did not clearly identify the rules until after trying to apply them to the facts. This did not work successfully and the student averaged a bare pass, with a best mark of $60 \%$ in the exam.

The remaining student who did not use IRAFT per se, in fact used a more sophisticated version of it. After identifying the issues, 
the student discussed the rules and their application to the facts in a clear and cogent manner, linking them through to the conclusion. Yet there was no specific identifiable order in the discussion. In my view it was representative of a developed structure, reflecting a more expert than novice interpretive framework. ${ }^{49}$ The student achieved an average in the top $14 \%$.

\section{What Makes a Good Student?}

The other students in that top $14 \%$ all used IRAFT well. Again, this in my view reflects a move towards using an expert interpretive framework. Many other factors will influence the consistent achievement of a good mark. However, in the light of the other results, the use of an effective structure to assist in the reasoning process stands out as a strong indicator of which students will generally achieve good marks and which will not.

The number of students who used a structure well increased from $50 \%$ in the first question to $64 \%$ in the exam question. The number of actual failures decreased from $22 \%$ in the first question to $6 \%$ in the exam question (refer Figure 2). It could be said that the exam conditions would result in better marks in any event. However, the correlation between the better marks and a "good" use of IRAFT or another structure cannot be ignored.

\section{Part 3: Conclusions ${ }^{50}$}

\section{WHY DO STUDENTS FAIL TO DELIVER IN THE EXAM?}

Consideration can now be given to the perceived problem that the quality of students' answers in examinations falls below the expectation of the markers. This research has in fact shown that in this course the students did deliver what was required of them in examinations. They did not fall apart and give sub-standard answers. In accordance with what should be expected of the teaching process, the students improved over the course and performed at their peak in the exam. Indeed, only the best students showed evidence of having acquired something of an expert interpretive framework. Yet, in my view, this is a totally appropriate result to expect from a course taken half way through a 
law degree.

\section{THE SUBJECTIVE VIEW}

As indicated in Part I of this article, there is a tendency for some law teachers to expect higher standards than in fact the majority of students are able to achieve. This could be explained in part by the fact that law teachers have "expert" interpretive frameworks in relation to their own subjects and find it difficult to relate to the "novice" interpretive approach taken by many students. ${ }^{51}$

Nonetheless, the objective research into the students' answers in this experiment, shows that students appeared to be progressing along the continuum of knowledge and application of that knowledge. The students did use the legal reasoning process taught; their marks were better because they used that process; and on an objective test of the marks, as checked by an independent marker, they performed to the standard expected. Indeed, most had not yet developed an "expert" interpretive framework. But they were progressing satisfactorily along the path to doing so.

Anecdotal evidence is not an adequate basis on which to give opinions or make decisions of substance. As discussed in Part I of this article, I and some of my colleagues perceived that students were failing to use structures given to them to assist in the development of their legal reasoning and, perhaps as a result, were producing poor answers to problems. It was on the basis of this anecdotal evidence that I undertook this research. The results suggest that the anecdotal evidence and subjective perceptions were largely false. ${ }^{52}$

\section{USING STRUCTURES TO TEACH LEGAL REASONING: SOME CAVEATS}

It is important to recognise that there are many difficulties which arise in teaching legal reasoning. The use of IRAFT will not solve these difficulties. Often, the fact patterns students are given to solve bear little relation to those faced by practitioners. Of necessity, as teachers try to present material to students in learnable, bite-sized chunks, problems are placed in boxes, such as "Contract" or "Tax". This is unlikely to happen in real life. Even when a problem given does purport to cover several areas of law, it 
is only usually final year law students who could hope to cope with all the legal nuances of most real-life fact patterns. ${ }^{53}$

A fact pattern presented to students also generally includes the material facts necessary to solve any problems arising in that fact pattern. Any missing facts are covered by the use of "assumptions". In a traditional law school program, the real life skills in drawing out and recognising facts material to a client's problem can be dealt with through training in other skills such as client interviewing and areas of dispute resolution.

Applying legal reasoning to problems raised in set fact patterns presupposes a certain knowledge base in the area of the law in which the problems are set. Simply providing students with a framework for legal reasoning will not generally be sufficient for someone with no knowledge in an area of law to solve a problem in that area. ${ }^{54}$ Furthermore, there is seldom, if ever, one right approach, one right analysis or one right answer to any legal problem.

Nonetheless, legal reasoning is an essential lawyering skill that law teachers want their students to learn. It is all very well to say that law teachers should introduce teaching methods which overcome the drawbacks to current methods of teaching legal reasoning and analysis, separate from the real world environment. For most undergraduate law school programs that is impractical given the funding and resources available. The important point is that law teachers need to be aware of the problems inherent in the methods in order to compensate for those shortcomings.

\section{THE RESULTS IN CONTEXT}

The IRAFT structure was chosen as being fairly representative of models developed for use in the legal reasoning process. ${ }^{55}$ In the experiment, the results showed that students did use the structure taught and its use in the legal reasoning process did assist students in their analysis of basic fact patterns. There was also a very strong relationship between use of the structure and the achievement of high marks. However, the structure was not necessarily consistently applied and it could probably be stated that consistent application would only occur with practice and experience, as the novice student moved towards the acquisition of an expert interpretive framework. 
Significant research needs to be undertaken into the teaching and learning of the legal reasoning process. Particular problems for students identified by this experiment were how to recognise the appropriate legal rules and how to apply those rules to the material facts. Useful study could be done on the best methods of using a structure in the teaching and learning of legal reasoning skills in the context of these particular problems.

As William Twining said:

"what is involved in teaching, learning and assessing individual professional skills is under-theorised and under-researched. The result is that almost everyone involved in general debates about professional competency and professional training ... do not really know what they are talking about ...".56

What also comes out of the experiment described in this article, is that empirical research can contradict the pure anecdote which can so easily shape the way skills are taught in law schools.

Legal reasoning is not some mystical talent given to the fortunate and favoured few. It is a skill to be taught as part of a structured and incremental curriculum, designed to best take the novice first year law student to the threshold of an expert interpretive framework, sufficient to equip that law student to step out into any one of the diverse jobs now open to lawyers.

\section{APPENDIX A}

\section{SAMPLE PROBLEM}

Gold Coast Machinery Ltd uses a complex and specifically designed electrical conveyor system which conveys machines to the loading dock, where it lifts them onto the trucks. The conveyor system was originally commissioned in 1984 and cost \$3.8 million. In 1994, the original gearbox, which formed part of the engine which runs the conveyor system, reached the end of its useful life. It was replaced by a new gearbox designed to present day technical standards.

The new gearbox cost $\$ 300,000$ and is being used in conjunction with the existing drive motors. It has been designed for future power upgrades but will only be able to increase the original design capacity of the machinery if new motors are fitted. This is 
expected to happen in 1995, once the current general upgrade to the machinery has been completed.

Is the gearbox replacement a repair to the machinery for section 53 ?

Write an answer to this problem of not more than one page. Bring the answer to your tutorial and it will be collected by your tutor.

\section{SAMPLE SOLUTION USING IRAFT}

The requirements of section 53 are met, with the possible exception that the expenditure incurred may be capital in nature. This is the issue to be determined in this question. (Issue)

Whilst numerous cases suggest that it is essentially a question of fact whether or not expenditure is of a capital nature, two principles have been established. (General Rule)

The expenditure must be incurred in relation to the renewal or replacement of a part and not of an entirety. (Rule)

In Lindsay v FCT a slipway in a shipyard was held to be an "entirety", being identifiable as a separate item of capital equipment. In contrast, the relaying of 74 out of some 394 miles of a railway line in order to remove specific defects and to restore the line to its normal condition, was held to be a repair to the railway line as a whole. The Privy Council in Rhodesia Railways Ltd $v$ Resident Commissioner \& Treasurer Bechuanaland Protectorate held that it was a periodical renewal and did not constitute a reconstruction of the whole railway. Rowlatt $\mathrm{J}$ in O'Grady $\mathrm{v}$ Bullcroft Main Collieries Ltd said that the identification of an "entirety" is largely a matter of impression and degree. (Rule)

In the present case it seems that the gearbox is part of the machinery rather than being a separate asset in its own right. Neither is it the major part of the machinery and unlike the slipway, it can be regarded as a mere component of the whole. (Application of the Rule to the Specific Facts and Tentative Conclusion)

The expenditure must not result in a substantial improvement, addition or alteration to the existing asset. (Rule) It was held in W Thomas \& Co Pty Ltd v FCT that a repair must restore an asset's efficiency in function without improving on it. Most cases illustrating the application of this principle relate to buildings and do not help in this case. (Rule) 
Although the gearbox is specifically designed for a future power upgrade, an improvement to the function of the machine can only occur with the installation of new motors. Accordingly, it is arguable that the new gearbox has not in itself resulted in a substantial improvement, addition or alteration to an existing asset. (Application to the Facts)

However, a substantial improvement may be effected by a series of piecemeal repairs, which should each then be regarded as capital expenditure (FCT $v$ Western Suburbs Cinemas Ltd). This is particularly so when the expenditure involved is substantial. (Rule)

As the new gearbox was installed as part of a wider plan to upgrade the machinery and the installation of new motors is anticipated as part of this upgrade, the replacement gearbox should be treated as a capital asset. (Application of the Rule to the specific Facts and Tentative Conclusion)

Accordingly, it is strongly arguable that the expenditure is not deductible as a repair under section 53. (Tentative Conclusion)

* Assistant Professor, School of Law, Bond University. This article was born out of the discussions of the Action Research Group in the Bond University Law School, who should take the credit for any good ideas. I would like to express my particular thanks to Associate Professor Kay Lauchland, Skills Co-ordinator in the Bond University Law School for her constant encouragement and helpful comments throughout the writing of this paper; Associate Professor Tapen Sinha of the School of Business at Bond University, for his useful comments and without whose input the statistical analysis and interpretation could not have been performed and Professor John Wade of the Bond University Law School, for his guidance and comment.

1 American Bar Association (ABA), Legal Education and Professional Development - An Educational Continuum, Report of the Task Force on Law Schools and the Profession: Narrowing the Gap (Illinois: American Bar Association, 1992). For an accessible review from an Australian perspective see EE Clark, Legal Education and Professional Development - An Educational Continuum, Report of the Task Force on Law Schools and the Profession: Narrowing the Gap, (Illinois: American Bar Association, 1992) (1993) 4 Legal Educ Rev 201.

$\mathrm{ABA}, i d$, at 8.

Id at $138-140$.

4 See for example, GW Paton \& DP Derham, A Text-book of Jurisprudence (4th ed., Oxford: OUP, 1972) ch 8; Lord Lloyd of Hampstead \& MDA Freeman, Lloyd's Introduction to Jurisprudence (5th ed., London: Stevens \& Sons, 1985) ch 12; M Davies, Asking the Law Question (Sydney: Law Book, 1994) ch 2; G Morris, C Cook, R Creyke \& R Geddes, Laying Down the Law (3rd ed., Sydney: Butterworths, 1992) Part Two; and FK Maher \& PL Waller, Derham, Maher, Waller: An Introduction to Law (6th ed., Sydney: Law Book, 1991) Part III.

5 Examples can be found many textbooks, such as IG Wallschutzky \& GL Payne (eds), Tax Questions and Answers (Sydney: Butterworths, 1994); L Griffiths, Corporations Law Workbook (Sydney: Law Book, 1994); S Graw, An 
Introduction to the Law of Contract (2nd ed., Sydney: Law Book, 1993) and of course a detailed discussion of the design of undergraduate problems is found in most introductory texts, such as Glanville Williams, Learning the Law (11th ed., London: Stevens \& Sons, 1986) ch 8 and Morris, Cook, Creyke \& Geddes, ibid, ch 3 .

6 "Experiments (which can be conducted either in laboratory or field settings) include those observational studies in which data are collected under conditions where behavioural choices are limited, or in some way constrained by the controlled manipulation of variables and measures selected by the researcher." WD Crano \& MB Brewer, Principles and Methods of Social Research (Newton: Allyn \& Bacon, 1986) 19.

Readers not interested in the detailed description of the research methodology may wish to read only the "Background" section in this part before moving to the second part.

8 S. Nathanson, The Role of Problem Solving in Legal Education (1989) $39 \mathrm{~J}$ Legal Educ 167.

9 See for example, BJ Ward, The Problem method at Notre Dame, (1958) $11 \mathrm{~J}$ Legal Educ 100, in which Ward' breaks the process down into 1) material fact identification; 2) issue identification; 3) rule identification; and 4) application of the rules to the facts. N Jackling, J Lewis, D Brandt \& R Sell, Problem Solving in the Professions, (1990) 9 Higher Education Research and Development, 133, use an algorithm to help structure the legal reasoning process. They use similar elements: 1) identification of the issues; 2) marshalling facts; and 3) applying the relevant law to the facts. The Bar Examiners' Handbook (2nd ed., 1980) at 287-291, quoted in M Josephson, Learning and Evaluation in Law School Vol 2 (Los Angeles: 1984) at 491-495, uses the elements: 1) analysis of the problem; 2) knowledge of the law; 3) application and reasoning; and 4) conclusions. The ABA Task Force Report, supra note 1, at 151-157, sets out in great detail the steps in the process of legal reasoning and analysis. They can be summarised broadly as: 1) analysis of the facts; 2) formulation of the legal issues; 3) identification and formulation of pertinent rules or principles of law; 4) application of the rules and principles to material facts; 5) formulation of relevant legal theories by analysing and synthesising the pertinent legal rules and principles in light of the facts; 6) elaboration and enhancement of legal theories; and 7) evaluation of the efficacy of legal theories in persuading decision makers to reach a particular result.

JH Wade, Meet MIRAT: Legal Reasoning Fragmented Into Learnable Chunks (1990-91) 2 Legal Educ Rev 283.

The idea for the research arose out of discussions with colleagues in a teaching interest group in the Law School at Bond University.

13 Readers not interested in the detailed research methodology should now move on to Part 2 of the article.

14 This aspect is one of many excellent points raised by Mitchell JB, Current Theories on Expert and Novice Thinking: A Full Faculty Considers the Implications for Legal Education (1989) 39 J Legal Educ 275 at 287. See further on this issue of novice versus expert thinking: RC Anderson, The Notion of Schemata and the Educational Enterprise, in RC Anderson, RJ Spiro \& WE Montague, (eds) Schooling and the Acquisition of Knowledge (NJ: Hillsdale, 1977), JB Biggs \& R Telfer, The Process of Learning (2nd ed., Sydney: Prentice-Hall of Australia, 1987) and Robert Glaser, Education and Thinking: The Role of Knowledge (1984) 39 Am Psychologist 93.

Anderson, id at 417-418.

Mitchell, supra note 14 at 277.

17 Glaser, supra note 14 at 98-99.

18 Mitchell, supra note 14 at 277. 
20 Ethical concerns arise as soon as students are used as the subjects of any experiment. Crano \& Brewer, supra note 6 at 323, state that "(t)he guidelines for psychological research set by the American Psychological Association's Committee on Ethical standards (1983) and by the President's Panel on Privacy and Behavioural Research (1967) stress the idea of recruiting subjects for such research on the basis of 'informed consent' — that is, that participation be voluntary and with the volunteer's full knowledge of what participation will involve."

FJ Landy \& DA Trumbo, Psychology of Work and Behaviour (Homewood: Illinois, 1980).

Refer for example, R Rosenthal, Experimenter Effects in Behavioural Research (New York: Appleton-Century-Crofts, 1966).

DT Campbell \& JC Stanley, in Experimental and quasi-experimental designs for research (Chicago: Rand-McNally, 1966) quoted in Crano \& Brewer, supra note 6 at 28-29, have identified eight major threats to the internal validity of any research program. These are: 1 ) history — intervening events; 2) maturation - changes in the subjects studied; 3) testing - previous exposure to the measurement; 4) instrumentation - changes in nature of measurement instrument; 5) statistical regression — unreliable measurement; 6) selection different selection procedures; 7) experimental mortality — varied dropout due to different treatment; 8) selection-history interactions - different selection procedures resulting in groups with different histories. The only one of these applicable to this experiment would be that the instrumentation varied. Using an exam question as the final test of the use of IRAFT may have resulted in distortion. Students may have performed differently because of the examination environment.

Students attended a one hour tutorial each week in groups of about 10 students. Attendance was high as tutorial performance made up $20 \%$ of the assessment. This could be classified loosely as a mixture of the "case" and "modified casebased" methods, two of the six categories of problem-based learning methods identified by $\mathrm{H}$ Barrows in A Taxonomy of Problem- Based Learning Methods (1986) 20 Medical Educ 481. For further discussion of Barrows' approach see inter alia, S Kurtz, M Wylie \& N Gold, Problem-Based Learning: An Alternative Approach To Legal Education, (1990) 13 Dalhousie Law J 797, and A Blunden, Problem- Based Learning And Its Application To In-House Law Firm Training (1990) 8 J of Professional Legal Educ 115 at 116-118.

27 This avoided the problem of initial observations influencing the interpretation of subsequent observations. Refer Crano \& Brewer, supra note 6 at 217.

28 The importance of this check lies in the converse of the Hawthorne effect or experimenter expectancy, namely experimenter bias. It is suggested that experimenters over-anxious to confirm their theoretical expectations may show bias in their recording, observation or computation of results. Refer Crano \& Brewer, supra note 6 at 90-92.

29 Reliability of measurement data in observational research such as this, is discussed further by KE Weick, Systematic Observational Methods, in G Lindzey \& E Aronson (eds), The Handbook of Social Psychology (3rd ed., Reading: Addison-Wesley, 1985).

30 Crano \& Brewer, supra note 6 at 218-228. See also, Weick, id at 38.

31 For readers unfamiliar with statistical analysis, it is important to note that the correlational statistics used here provide information on the association, if any, between two variables: the use of IRAFT and the marks achieved. They cannot tell us that the use of IRAFT caused students' marks to improve. They can only say that if students use IRAFT well, it is, say, 95\% certain that their marks will improve. See further, SK Kachigan, Statistical Analysis (New York: Radius 
Press, 1986) ch 10. For this experiment, the data was arranged into the three categories: first question, second question, exam question. The use of IRAFT was graded as good, satisfactory and poor. For the purpose of Pearson Product Moment Correlation, good was assigned the number 3, fair the number 2 and poor the number 1 . This assignment was subjective in that there is no statistical basis for saying that satisfactory use of IRAFT is twice as good as poor use of IRAFT etc. For Spearman Rank Correlation the ranking assigned was: good, 4; satisfactory, 3; poor, 2; and other or no method used, 1. The Use heading refers to the use of IRAFT in each of question 1, question 2 and the exam. The Q1, Q2 and Exam headings refer to the pure marks for each of the questions.

The results were as follows:

\begin{tabular}{|c|c|c|c|c|c|c|}
\hline & Use Q1 & Use Q2 & Use $\mathbf{E}$ & Q1 & Q2 & Exam \\
\hline \multicolumn{7}{|c|}{ Pearson Product-Moment Calculation } \\
\hline Use Q1 & 1.000 & & & & & \\
\hline Use Q2 & 0.454 & 1.000 & & & & \\
\hline Use E & 0.248 & 0.487 & 1.000 & & & \\
\hline Q1 & 0.680 & 0.413 & 0.095 & 1.000 & & \\
\hline Q2 & 0.319 & 0.340 & 0.249 & 0.447 & 1.000 & \\
\hline Exam & 0.070 & 0.194 & 0.493 & 0.224 & 0.255 & 1.000 \\
\hline \multicolumn{7}{|c|}{ Spearman Rank Correlation } \\
\hline Use Q1 & 1.000 & & & & & \\
\hline Use Q2 & 0.492 & 1.000 & & & & \\
\hline Use E & 0.199 & 0.550 & 1.000 & & & \\
\hline Q1 & 0.724 & 0.492 & 0.164 & 1.000 & & \\
\hline Q2 & 0.297 & 0.501 & 0.359 & 0.410 & 1.000 & \\
\hline Exam & 0.147 & 0.255 & 0.530 & 0.250 & 0.295 & 1.000 \\
\hline
\end{tabular}

32 Refer supra note 14 and see also: R Rosenthal \& KL Fode, Three Experiments in Experimenter Bias, (1963) 12 Psychological Reports, 491; and R Rosenthal \& L Jacobson, Pygmalion in the Classroom (New York: Holt, Rinehart \& Winston, 1968). 0.23 .

Twenty five out of the 39 students who used IRAFT.

Twenty six out of the 46 students who used IRAFT.

Thirty two out of the 48 students who used IRAFT.

Three out of the 39 students who used IRAFT.

Two out of the 46 students who used IRAFT.

Four out of the 48 students who used IRAFT.

Mitchell, supra note 14.

Id at 283-296.

Glaser, supra note 14 at 101.

Two students changed from IRAFT to other methods.

The correlation between Q1 and Q2 was 0.447 and Q1, Q2 and the exam was

There were F-ratios of 16.0 for Q1,6.82 for Q2 and 11.5 for the exam.

There was an F-ratio of 27.9.

There was an F-ratio of 2.45, giving a 7\% chance of error in the correlation.

There was an F-ratio of 1.87.

There was an F-ratio of 1.34. An F-ratio of less than 2 has been taken as unacceptable in showing evidence of correlation. 
Refer Mitchell, supra note 14.

50 It must be emphasised that this experiment is only the first step in showing that use of structures by students will improve their legal reasoning. The inference can be drawn from the results of the experiment that the hypothesis may be true. Further experimentation is required, primarily through falsification of as many competing hypotheses as possible. For example, the hypothesis should be tested that students' legal reasoning will improve to the same extent without the use of a structure. See Crano \&Brewer, supra note 6, for a discussion of the principles and methods which should be followed.

51 This would certainly flow from the analysis by Mitchell, supra note 14.

52 This is not unique to legal education. Cf the report by P Williams, R Williams, A Goldsmith \& P Browne, The Cost of Civil Litigation Before Intermediate Courts in Australia (AIJA 1992), in which it was stated with reference to procedural reform in the civil litigation process: “(w)hat makes matters even more difficult is that reform challenges the often longstanding practices and preferences of participants. More often than not, these practices are justified on the basis of personal experience without the wider reference point of empirical research.

53 This may well be different in law schools using curricula which try and overcome this specific problem, such as occurs in some clinical programs.

54 Mitchell, supra note 14 at 289

55 For discussion of the various models used see supra note 9.

56 W Twining, Taking Skills Seriously (1986) 4 Jnl Prof Leg Ed 1. See also, C Roper, Issues in Skills Training in Australia, an as yet unpublished paper presented at the 1994 Professional Legal Skills Conference, held at Bond University 10-11 February 1994. 